\title{
Some possible correlations between electro-magnetic emission and seismic activity during West Bohemia 2008 earthquake swarm
}

\author{
P. Kolář \\ Institute of Geophysics, Boční II 1341, Prague 4, Spořilov, 14131, Czech Republic \\ Received: 26 March 2010 - Published in Solid Earth Discuss.: 12 April 2010 \\ Revised: 22 July 2010 - Accepted: 2 September 2010 - Published: 6 October 2010
}

\begin{abstract}
A potential link between electromagnetic emission (EME) and seismic activity (SA) has been the subject of scientific speculations for a long time. EME versus SA relations obtained during the 2008 earthquake swarm which occurred in West Bohemia are presented. First, a brief characterisation of the seismic region and then the EME recording method and data analysis will be described. No simple direct link between EME and SA intensity was observed, nevertheless a deeper statistical analysis indicates: (i) slight increase of EME activity in the time interval 60 to $30 \mathrm{~min}$ before a seismic event with prevalent periods about $10 \mathrm{~min}$, (ii) some gap in EME activity approximately $2 \mathrm{~h}$ after the event, and (iii) again a flat maximum about $4 \mathrm{~h}$ after the seismic events. These results qualitatively correspond with the observations from other seismically active regions (Fraser-Smith et al., 1990). The global decrease of EME activity correlating with the swarm activity decay was also observed. Due to the incomplete EME data and short observation time, these results are limited in reliability and are indicative only.
\end{abstract}

\section{Introduction}

An earthquake, apparently pure mechanic phenomenon, has been for a long time suspected to generate not only seismic but also electromagnetic waves. An attempt in detecting electromagnetic phenomena generated by earthquakes in West Bohemia earthquake region during an intensive earthquake swarm 2008 will be described. A brief description of the earthquake region and the measurement technology (both seismic and electromagnetic) will be given and, finally, possible mutual correlations will be discussed.

\subsection{West Bohemia earthquake region}

Seismic activity in West Bohemia (hereafter WB) region is definitely the most important seismic phenomenon of the Czech Republic. The activity is characterised by a repeated occurrence of weak earthquake swarms. It was most recently affirmed by the 2008 swarm, the strongest one in the last 3 decades. High activity lasted approximately from 10 October to 5 November 2008. More than 20000 events $(\mathrm{Ml}>-0.5)$ were recorded, from which about 100 events had magnitude $\mathrm{Ml}>2.0$ (the strongest one with magnitude $\mathrm{Ml}=3.7$ ). Automatically identified and localized events are depicted in Figs. 1 and 2.

The region is monitored by WEBNET seismic network (Horálek et al., 2000) and the activity is consequently the subject of intensive studies (see among other e.g. Stud. Geophys. Geod., 2000, 2008, 2009). Current information regarding the seismic activity in the region is posted on Webnet (2010) www pages.

In the beginning of modern instrumental investigation, which can be dated back to the 1985/1986 swarm, the effort was focused on exclusive seismic monitoring (operating the network of local seismic stations, data collection, processing and archiving). In the last decade, in addition to the above mentioned "classical" seismic monitoring, various attempts appeared to investigate non-seismic phenomena and their relation to the seismic activity (Špičák, 2000). As an example, observations of $\mathrm{CO}_{2}$ gas emanation (e.g. Faber et al., 2009), gravimetric measurements (Mrlina and Seidl, 2008; Kämpf, et al., 2008), GPS measurements (Schenk et al., 2009), micro-network observation (Häge and Joswig, 2008). We made an attempt to record the electromagnetic emission (here after EME) excited by seismic activity.

\section{Correspondence to: P. Kolár}

(kolar@ig.cas.cz)

Published by Copernicus Publications on behalf of the European Geosciences Union. 

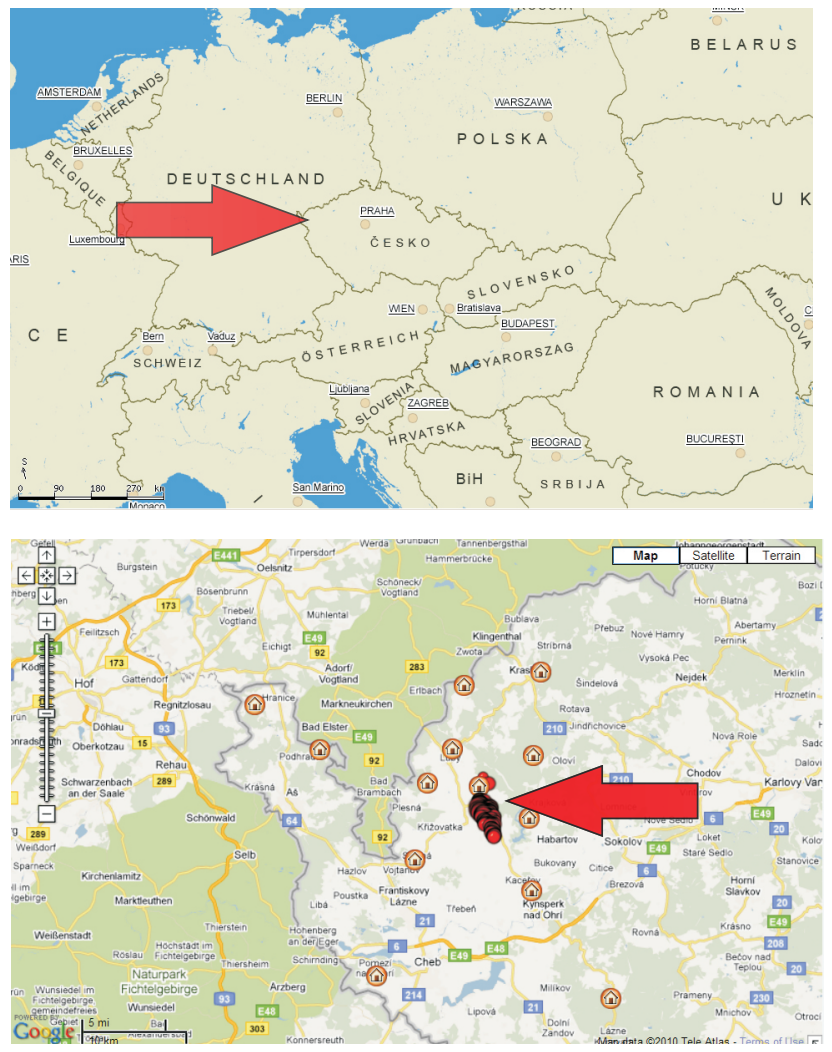

Fig. 1. Upper part: Position of West Bohemia region in Central Europe (marked by red arrow). Lower part: A print-screen of interactive (detailed) "Map of West Bohemia earthquake region". There are plotted stations of WEBNET network (symbol house) and 2008 earthquake swarm epicentres for $\mathrm{Ml}>1.8$ (red circle). Taken from Epicentre map (2010).

\subsection{Possible relation between seismic activity and electromagnetic emission}

A relation between seismic activity and electromechanic phenomena has been referred to in the literature for a long time (Eftaxias et al., 2001; Karakelian et al., 2002; Matsushima et al., 2002; Kapiris et al., 2003). Unfortunately, these references are either uncertain, unparalleled only (with no repetition of observation of the phenomenon), observation conditions are insufficiently described or the particular phenomenon is handled only qualitatively, etc. The effects comprise of the lights (St-Laurent et al., 2006; Losseva and Nemchikov, 2005), flashes, storms and ionosphere changes excited by large earthquakes (excitation is supposed to be transferred via the Earth's surface vibrated by surface waves; Guglielmi et al., 2006a,b). Exhaustive review of electric and magnetic field observations accompanying seismic and volcanic activity is given in Johnston (1997). Some laboratory experiments have also been performed (T. Lokajíček, personal communication, 1998). There are also speculations about the existence of electromagnetic precursors to

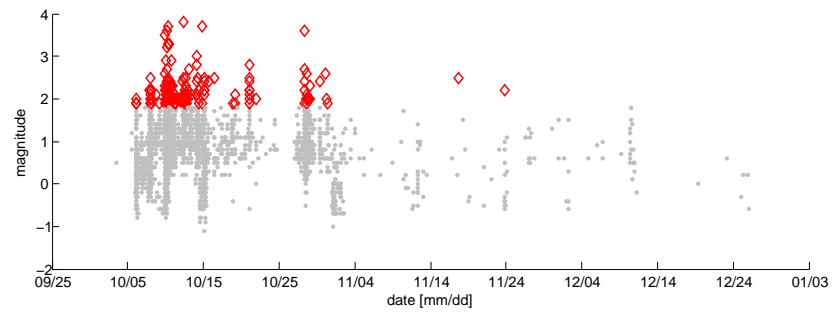

Fig. 2. Activity of 2008 West Bohemia earthquake swarm. There are plotted events' magnitudes versus time of all the bulletin events: $\mathrm{Ml}>1.8$ marked by a red diamond (events considered in the presented study), weaker events by gray dots.

earthquakes or EME excited by material destruction during the earthquake rupture process (Freund et al., 2006; Vallianatos et al., 2004).

\section{EME observations}

The earthquake swarm activity in 2008 (since 10 October 2008) was the final impulse to also install the EME measurement in the West Bohemia region to the ongoing regular seismic registration. The instrument was installed during the course of the 2008 swarm (on 14 October 2008) at the seismic station Nový Kostel (NKC) situated directly in the epicentral zone. The instrument consists of coil antenna, amplifier and digitizer. The coil antenna contains about 20000 turns around permealoid core, frequency range of the instrument is about $0.2-10 \mathrm{~Hz}$ with a sampling rate of $25 \mathrm{~Hz}$, continuous registration. The antenna is sensitive to $\mathrm{H}$ component of the electromagnetic field. The daily EME data volumes were regularly downloaded from NKC station.

\section{EME data mining}

Preliminary visual analysis of the recorded EME showed pronounced correlation between EME signal and strong events (i.e. with $\mathrm{Ml}>2.0$ ), about 15 such cases were observed during the course of measurement. By compariing with corresponding seismograms, it was discovered that the strong EME signals are exactly correlated with $P$ and/or $S$ waves arrivals at the station, thus, the observed anomalies are only so called "microphone effects" caused by the movement of the antenna in the magnetic field (Earth's magnetic field possibly distorted by earthquake-initiated movement of the near metallic parts of the station construction). Provided that EME could be connected with earthquake rupture process, we stacked EME signals related to the relevant earthquakes: the considered intervals of EME signals were "centred" around their origin times.

$\operatorname{sumEME}_{(-d t,+d t)}=\sum_{i=1: N} \operatorname{EME}_{\left(T 0_{i}-d t, T 0_{i}+d t\right)}$, 


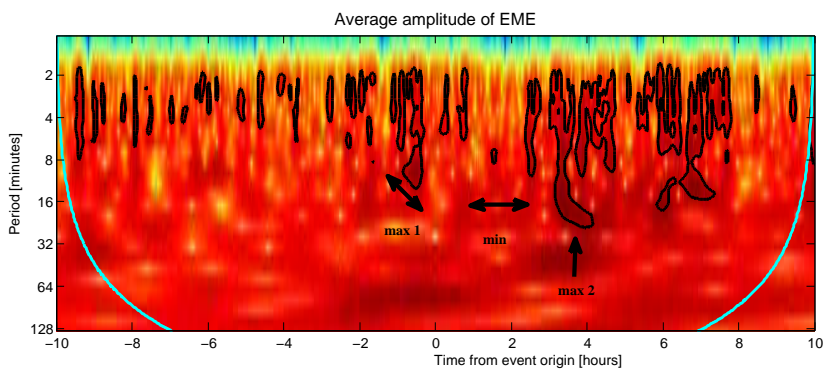

Fig. 3. Wavelet spectrum of summed EME signal (minute averages of time series are used) in range $d t= \pm 10 \mathrm{~h}$ round the origin time. 47 events (with $\mathrm{Ml}>1.8$ ) were processed. Algorithm designed by Torrence and Copmpo (1998) or Wavelet (1998) was used. The cyan lines determine zones of spectrum reliability, extremes with statistical significance $>0.95$ are marked by black lines. Increase of EME activity before the event is marked by double arrow and named "max 1", gap after the event is marked by double arrow and named "min", the following maximum is marked by arrow and named "max 2 ".

where sumEME is the final stacked signal of length $2 \times d t, T 0_{i}$ is the origin time of $i$-th event $(i=1: N)$, $\operatorname{EME}_{(T 0 i-d t, T 0 i+d t)}$ is the particular interval of EME signal from time $T 0_{i}-d t$ time to $T 0_{i}+d t$. Neither stacked signal, nor its spectral or wavelet analysis showed any (positive) correlations or anomalies. The range of stacked EME signals $d t$ varied from 5 to $50 \mathrm{~s}$, again only events with $\mathrm{Ml}>2.0$ were processed. More precisely, some anomalies were observed in wavelet spectra, but they appeared to be unstable if $d t$ interval varied. Therefore, we classified those extremes as random artifacts, rather than real effects. Consequently, we conclude that we did not observe any direct correlation between EME signal and seismic events.

\subsection{Data stacking}

We applied the approach of Georgiadis et al. (2009) in order to further exploit EME data statistics: data is transformed into one minute amplitude average, which is, in fact, a kind of data filtration and decimation. Even if data of different frequency range (20 MHz sampling) are processes in the quoted work, we applied the same processing chain in our dataset as well. Then we made a summation again given by Eq. (1) considering time range $d t$ was $\pm 10 \mathrm{~h}$. The final wavelet spectrum is in Fig. 3. It follows that: (i) there is an increase of EME activity in the time window from -3 to $0 \mathrm{~h}$ before the occurrence of a seismic event with a maximum time from -1 to $-0.5 \mathrm{~h}$ before an event; prevalent period of the maximum is about $10 \mathrm{~min}$. Note that this maximum is generated preferably by events with a magnitude of about $\mathrm{Ml} \sim 2.0$ rather than by the stronger events (this effect is not displayed in the figure). (ii) There is a gap of EME in the time window from +1 to $+2 \mathrm{~h}$ after the seismic event. (iii) Finally, there is a pronounced maximum in time of about $+4 \mathrm{~h}$ after a seismic
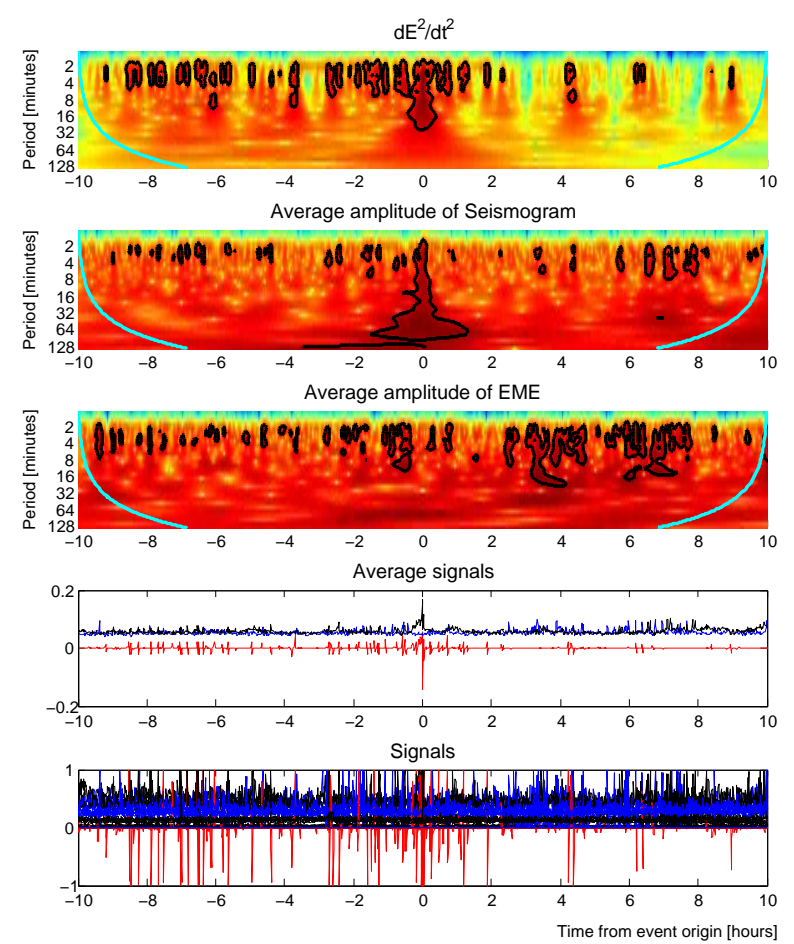

Fig. 4. Exclamation of "microphone effect". Wavelet spectra (from the top) of velocity energy release (a), seismograms (b) and EME signal (c) (the same as in Fig. 3) are plotted. At the bottom there are normalized processed signals (e): red - energy release, blue EME, black - seismogram, and their averages (d) meaning of the colours is the same as in (e) - i.e. input data for wavelet analysis. The energy release and seismograms have maxima round the origin time (time $=0$ ) as it can be expected and there is no correlation with extremes observed in EME signal. Therefore, we concluded that extremes observed in EME signal are not caused by any "microphone effect" provoked by arriving seismic waves at the station.

event with a prevalent period of about $16 \mathrm{~min}$. The stability of this maximum was tested and confirmed by Bootstrap test.

As far as some anomalies were observed in wavelet spectra of the stacked signal, we wanted to be sure they were not again a "microphone effects". It could be the case, e.g. if there is some prevailing period of event repetition during the course of the swarm. To test this hypothesis, we constructed another two stacked signal: (i) we stacked seismic signals the same way as EME signals. We used broadband seismic recordings from station Nový Kostel for this analysis (sampling frequency of seismic signal was $20 \mathrm{~Hz}$ which is close to that of EME $-25 \mathrm{~Hz}$ ). The corresponding wavelet spectrum is in the Fig. 4b, $Z$ component of seismogram was used.

(ii) We supposed that EME anomalies could be the effect of week but numerous swarm events. Therefore, we constructed a cumulative graph of energy release. All bulletin events (WEBNET 2008, 2010) were included using standard equation

$\log E=1.5 \mathrm{Ml}+11.8$ 
i.e. Gutenberg-Richter magnitude-energy relation was used. These values are growing in time and its time derivative too. Therefore, we calculated second time derivative to obtain an oscillatory signal. In such a way we obtained the change of energy release velocity (or, figuratively, we can also speak about "energy acceleration"). Then the values were interpolated with an equidistant time step and processed in the same way as EME signal. The wavelet analysis of that signal is in Fig. 4a. Neither analysis of the seismic signal nor the velocity of energy release showed a correlation to the stacked EME signal extremes. We, therefore, concluded, as follows from the Fig. 4, that observed EME anomalies are not caused by "microphone effect" nor by a cumulating effect of numerous week events and, thus, we observed actual changes of EME.

Note that microphone effect connected with $P$ and/or $S$ waves arrivals, mentioned in the beginning of Sect. 3, cannot be visible here. The duration of the microphone pulse is only a few seconds, which is far below the resolution limit of wavelet spectra having a sampling period of $1 \mathrm{~min}$.

\subsection{Global trend}

In the next analysis, we calculated STA/LTA ratio ${ }^{1}$ of EME for the whole swarm (approx. 3 months) and compared it with the swarm earthquake activity - see Fig. 5. The time windows of STA $=10$ samples and LTA $=100$ samples were used. It is obvious from the figure, that the frequency of STA/LTA picks generally decreases with the swarm activity decay.

Extremes in STA/LTA ratio correspond to the presence of a signal in the EME data, nevertheless the origin of these signals is unknown. We can only speculate that it can be somehow connected to the course of the earthquake swarm activity. We tried to eliminate the influence of global or ionospheric effects in the following way: we processed magnetic measurements (of $1 \mathrm{~s}$ sampling) from the geomagnetic observatory Budkov (located approx. $170 \mathrm{~km}$ ES from the Nový Kostel station). The Budkov data were processed in the same way as our EME data, the result is presented in Fig. 5. It follows from the figure, that extremes observed at NKC station do not coincide with those at Budkov, therefore, they are not of global or ionospheric origin. Of course this analysis can neither confirm nor reject "earthquake" origin of the observed extremes. There is still a possibility they are generated by local industry, namely by mining brown coal in quarries and the decrease of activity can be the consequence, e.g. by the decrease of mine activity during winter time and/or by the end of the year.

\footnotetext{
${ }^{1}$ STA/LTA - ratio of Short Time Average/Long Time Average - a standard way used in seismology to detect the occurrence of a signal in (noisy) seismogram. The algorithm can deal with a slow increase/decrease of noise levels in the signal. On the other hand in its simplest form it cannot handle together with different types of signals as e.g. teleseismic events versus local ones.
}

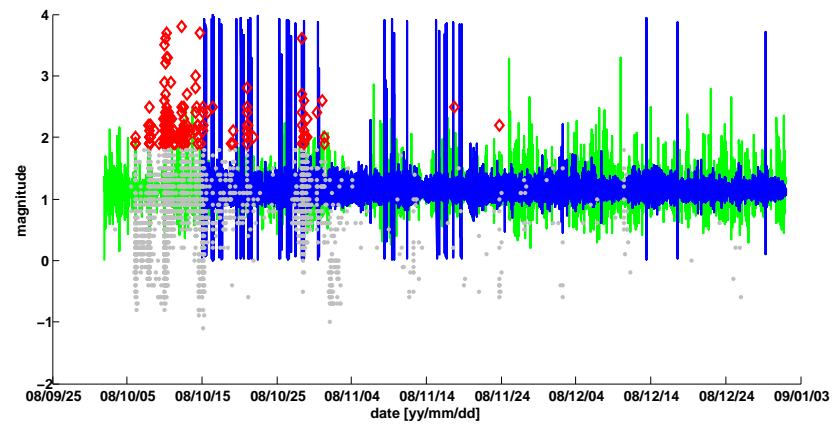

Fig. 5. Decrease of EME activity during the swarm course: the same as Fig. 2, but STA/LTA ratio of averaged EME signal is added (blue line). The decrease of STA/LTA EME signal picks with the decrease of the swarm activity is obvious. To exclude possible influence of global sources of extremes, data from Budkov station are plotted (green line).

\section{Conclusions}

We started measurements of electromagnetic emission (EME) in the West Bohemia earthquake region and recorded data during part of the 2008 seismic swarm. It is a new nonseismic measurement in the region.

Data analysis showed:

- there is no direct correlation between earthquake occurrence and EME anomalies

- statistical increase of EME activity from time -3 to $0 \mathrm{~h}$ before the seismic event with the maximum in time -1 to $-0.5 \mathrm{~h}$ with prevalent periods about $10 \mathrm{~min}$ was observed

- statistical gap of EME activity in time +1 to $+2 \mathrm{~h}$ after the seismic event exist

- statistical maximum of EME activity in time $+4 \mathrm{~h}$ after the seismic event exist with prevalent period about $16 \mathrm{~min}$

- possibility of extremes caused by "microphone effect" were practically excluded

- decrease of picks of STA/LTA ratio of EME signal during the swarm course were observed; even if the source of the abnormalities in EME signal is rather questionable, they do not seem to be of global origin

On the basis of previous laboratory experiments ( $\mathrm{T}$. Lokajíček, personal communication, 1998), we can speculate that the increase of EME activity before a stronger event can be a preparation phase of the process. The after event gap can be a quiet phase of the relaxation. We have no such hypothesis for the EME activity maximum after the seismic event and its explication needs new formulation of preparation and healing of the earthquake process. 
M. JOHNSTON

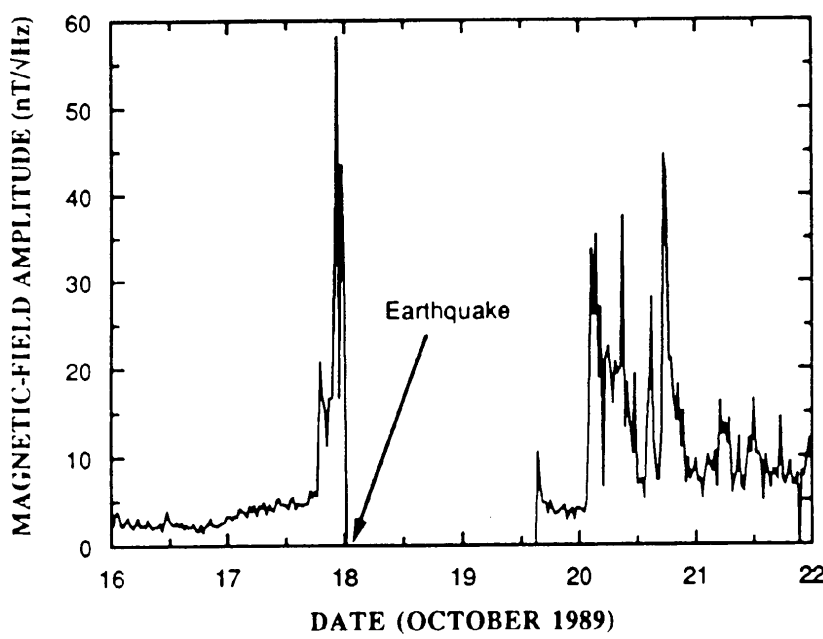

Fig. 6. Magnetic field amplitude as a function of time during the 2 days before and 4 days after the Loma Prieta earthquake (from Fraser-Smith et al., 1990, quoted also in Johnston, 1997). We consider the observed magnetic field amplitudes qualitatively similar to our results (cf. Fig. 3), of course in different time scale.

All presented results must be understood as advice to a promising direction in future investigations rather than as final fully confirmed facts, namely due to these points: (i) the observations did not cover the whole swarm and did not include its strongest event, (ii) we also do not have EME data before the swarm, (iii) EME were recorded during only one swarm, and (iv) only at one point of observation. Nevertheless, it is remarkable that the observed course of EME activity in relation to seismic activity (i.e. an increase before the event, a gap immediately after the event and then again an increase) quantitatively corresponds to observed magnetic field amplitudes tied with Loma Prieta earthquake $\left(M_{\mathrm{S}}=7.1\right.$, 17 October 1989), of course in a different time scale - see Fraser-Smith et al. (1990) and Fig. 6.

We consider all these results as promising and challenging and for these reasons we plan: (i) to continue in EME measurements, (ii) to broaden the frequency range, and (iii) to increase the number of observation points including some situated also out of the seismoactive region for distinguishing possible local and regional EME components.

Further information is available also at EME project (2010) www pages.

Acknowledgements. The project of EME measurement in WB region has not yet any direct official support and, therefore, all the work can be performed only due to enthusiasm and effort of the following people. Thanks goes particularly to: J. Horáček, leader of WEBNET group, for spiritual, materialistic and financial support of the project, P. Jedlička for technical help. A. Boušková for kindly providing WEBNET seismic bulletins and comments, F. Hruška, J. Baše, and J. Chum (all three from the Institute of Atmospheric Physics of Czech Acad. of Sci., department of Upper Atmosphere) for the construction of special coil antenna and technical help, L. Vecsey for wavelet transform consultations, J. Horáček for kindly providing Budkov magnetic data, B. Rủžek for general comments. Thanks to two reviewers (anonymous one and W. Geissler) for their helpful comments.

The EME data analysis was supported by grant IAA300120805 of Grant Agency of Czech Republic.

Edited by: R. Kind

\section{References}

Eftaxias, K., Kapiris, P., Polygiannakis, J., Bogris, N., and Kopanas, J. G.: Signature of pending Earthquake from Electromagnetic Anomalies, Geophys. Res. Lett., 28(17), 3321-3324, 2001.

EME project: http://www.ig.cas.cz/kolar/EME/, last access: 30 June, 2010.

Epicentre map: http://www.ig.cas.cz/cz/struktura/observatore/ webnet/mapa-ohnisek/, last access: 25 March, 2010.

Faber, E., Horálek, J., Boušková, A., Teschner, M., Koch, U., and Poggenburg, J.: Continuous gas monitoring in the West Bohemia Earthquake area, Czech Republic: first results, Stud. Geophys. Geod., 53(4), 315-328, 2009.

Fraser-Smith, A. C., Bernardi, A., McGill, P. R., Ladd, M. E., Helliwell, R. A., and Villard Jr., O. G.: Low-frequency magnetic field measurements near the epicenter of the MS 7.1 Loma Prieta earthquake, Gophys. Res. Lett., 17(9), 1465-1468, 1990.

Freund, F. T., Takeuchi, A., and Lau, B. W. S.: Electric currents streaming out of stressed igneous rocks - A step towards understanding pre-earthquake low frequency EM emissions, Phys. Chem. Earth Pt. A,B,C, 31(4-9), 389-396, 2006.

Georgiadis, P., Cavouras, D., Sidiropoulos, K., Ninos, K., and Nomocos, C.: Remote monitoring of electromagnetic signals and seismic event using smart mobile devices, Comput. Geosci., 35, 1296-1308, 2009.

Guglielmi, A., Hayakawa, M., Potapov, A., and Tsegmed, B.: Polarization method to detect the co-seismic magnetic oscillations, Phys. Chem. Earth Pt. A,B,C, 31(4-9), 299-304, 2006 a.

Guglielmi, A., Potapov, A., Tsegmed, B., Hayakawa, M., and Dovbnya, B.: On the earthquake effects in the regime of ionospheric Alfvén resonances, Phys. Chem. Earth Pt. A,B,C, 31(49), 469-472, 2006b.

Häge, M. and Joswig, M.: Microseismic study using small arrays in the swarm area of Nový Kostel: Increased detectability during an inter-swarm period, Stud. Geophys. . Geod., 52(4), 661-672, 2008.

Horálek, J., Fischer, T., Boušková, A., and Jedlička, P.: The Western Bohemia/Vogtland Region in the Light of the Webnet Network, Geophys. Geod., 44(2), 107-125, 2000.

Johnston, M. J. S.: Review of electric and magnetic fields accompanying seismic and volcanic aktivity, Surv. Geophys., 18, 441475, 1997.

Kämpf, H., Heuer, B., Mrlina, J., and Reuther, H.: Combined xenolith and receiver function study, western Bohemian Massif, Central Europe, Geochim. Cosmochim. Acta, 72(12), Supplement 1, A 447, 2008.

Kapiris, P. G., Eftaxias, K. A., Nomikos, K. D., Polygiannakis, J., Dologlou, E., Balasis, G. T., Bogris, N. G., Peratzakis, A. S., and 
Hadjicontis, V. E.: Evolving towards a critical point: A possible electromagnetic way in which the critical regime is reached as the rupture approaches, Nonlinear Proc. Geoph., 10(6), 511-524, 2003.

Karakelian, D., Beroza, G. C., Klemperer, S. L., and Fraser-Smith, A. C.: Analysis of Ultralow-Frequency Electromagnetic Field Measurements Associated with the 1999 M 7.1 Hector Mine, California, Earthquake Sequence, Bull. Seism. Soc. Am., 92, 1513-1524, 2002.

Losseva, T. V. and Nemchinov, I. V.: Earthquake lights and rupture processes, Nat. Hazards Earth Syst. Sci., 5, 649-656, doi:10.5194/nhess-5-649-2005, 2005.

Matsushima, M., Honkura, Y., Oshiman, N., Baris, S., Tunçer, M. K., Tank, S. B., Çelik, C., Takahashi, F., Nakanishi, M., Yoshimura, R., Pektas, R., Komut, T., Tolak, E., Ito, A., Iio, I., and Isikara, A. M.: Seismoelectromagnetic Effect Associated with the zmit Earthquake and Its Aftershocks, Bull. Sekem. Soc. Am., 92, 350-360, 2002.

Mrlina, J. and Seidl, M.: Relation of surface movements in West Bohemia to earthquake swarms, Stud. Geophys. Geod., 52(4), 549-566, 2008.

St-Laurent, F., Derr, J. S., and Freund, F. T.: Earthquake lights and the stress-activation of positive hole charge carriers in rocks, Phys. Chem. Earth Pt. A,B,C, 31(4-9), 305-312, 2006.
Schenk, V., Schenková, Z., and Jechumtálová, Z.,: Geodynamic pattern of the West Bohemia region based on permanent GPS measurements, Stud. Geophys. Geod., 53, 329-341, 2009.

Stud. Geohpys. Geod.: Special issue devotes to West Bohemia topics, 44, 2-3, 2000.

Stud. Geohpys. Geod.: Sspecial issue devotes to West Bohemia topics - Part 1, 52, 4, 2008.

Stud. Geohpys. Geod.: Special issue devotes to West Bohemia topics - Part 2: 53, 3, 2009.

Špičák, A.: Earthquake Swarms and Accompanying Phenomena in Intraplate Regions: A Review, Stud. Geophys. Geod., 44(2), 89106, 2000.

Torrence, C. and Compo, G. P.: A Practical Guide to Wavelet Analysis, B. Amer. Meteorol. Soc., 79, 61-78, 1998.

Vallianatos, F., Triantis, D., Tzanis, A., Anastasiadis, C., and Stavrakas, I.: Electric earthquake precursors: from laboratory results to field observations, Phys. Chem. Earth Pt. A,B,C, 29(49), 339-351, 2004.

Wavelet: http://paos.colorado.edu/research/wavelets/, last access: 25 March 2010, 1998.

Webnet: http://www.ig.cas.cz/en/structure/observatories/ west-bohemia-seismic-network-webnet/, last access: 30 June, 2010.

WEBNET 2008: http://www.ig.cas.cz/userdata/files/observatories/ webnet/web2008.htm, last access: 30 June, 2010. 